\title{
Distal radyoulnar eklem instabilitesinde rekonstrüksiyon yöntemleri
}

\section{Reconstruction methods for distal radioulnar joint instability}

\author{
Ethem Ayhan Ünkar, Kahraman Öztürk \\ Sağlık Bilimleri Üniversitesi, Metin Sabancı Baltalimanı Kemik Hastalıkları Eğitim ve Araştırma Hastanesi, \\ El Cerrahisi Kliniği, İstanbul
}

\begin{abstract}
Distal radyoulnar eklem (DRUE), radiusun sigmoid çentiği ile ulna başının oluşturduğu sinovyal bir eklem olup ön kolun rotasyon hareketlerinden sorumludur. Eklemi oluşturan kemik yapıların eklem stabilitesi üzerindeki etkisi kısıtlı olup DRUE'nin ana stabilizatörü distal radyoulnar (DRU) bağlardır. Travmatik veya travma dışı nedenlere bağlı olarak gelişebilen DRUE instabilitesi hastalarda ağrıya, ön kol rotasyon kısıtlılığına ve kavrama gücünde azalmaya neden olabilmektedir. DRUE instabilitesinin tanısı ve tedavisi hekimler için zorlayıcı bir konu olmaya devam etmektedir. Distal radyoulnar eklem instabilitesi tanısında fizik muayene, provokatif testler ve radyolojik değerlendirmenin dikkatlice yapılması önemlidir. Son dönemlerde DRUE anatomisi ve biyomekaniği üzerine yapılan çalışmaların neticesinde DRUE instabilitesinin tedavisi için ulna başı rezeksiyonu gibi kurtarıcı işlemler yerini eklem anatomisinin ve fonksiyonlarının normale en yakın şekilde geri kazandırılabildiği bağ rekonstrüksiyonlarına bırakmıştır. Anatomik olmayan bağ rekonstrüksiyonu yöntemleri, distal radius ve ulnanın tendon greftleri ile birbirlerine askı yöntemleri ile tespit edilmesi, distal ulnanın tenodez ile stabilize edilmesi veya ulnokarpal bağın rekonstrüksiyonu olarak sıralanabilir. Volar ve dorsal radyoulnar bağların anatomik yapışma yerlerine rekonstrükte edildiği anatomik bağ rekonstrüksiyonu yöntemleri ile normal kinematiğe en yakın sonuçlar elde edilebilmektedir. El bileği artroskopisindeki ilerlemeler neticesinde anatomik bağ rekonstrüksiyonları artroskopi destekli olarak yapılabilmektedir.
\end{abstract}

Anahtar sözcükler: distal radyoulnar eklem; instabilite; rekonstrüksiyon; el bilek artroskopisi
Distal radioulnar joint (DRUJ) is a synovial joint formed by the sigmoid notch of the radius and the head of the ulna, and is responsible for the rotational movements of the forearm. The effect of the bony structures on joint stability is limited and DRUJ's main stabilizer is the DRU ligaments. Distal radioulnar joint instability, which can develop due to traumatic or non-traumatic reasons, may cause pain, limitation of forearm rotation and decrease in grip strength in patients. The diagnosis and treatment of DRUJ instability is a challenging issue for physicians. In the diagnosis of DRUJ instability, careful physical examination, provocative tests and radiological evaluation are important. As a result of recent studies on DRUJ anatomy and biomechanics, salvage procedures such as ulnar head resection have been replaced by ligament reconstructions where joint anatomy and functions can be restored as close to normal for the treatment of DRUJ instability. Non-anatomical ligament reconstruction methods can be listed as tethering distal radius and ulna with tendon grafts, stabilizing the distal ulna with tenodesis, or reconstruction of the ulnocarpal ligament. Anatomic ligament reconstruction methods, in which volar and dorsal radioulnar ligaments are reconstructed to their anatomic attachment sites, can yield results that are close to normal kinematics. As a result of advances in wrist arthroscopy, arthroscopic-assisted anatomical ligament reconstructions can be performed

Key words: distal radioulnar joint; instability; reconstruction; wrist arthroscopy

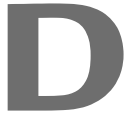

istal radyoulnar eklem (DRUE), radiusun sigmoid çentiği ile ulna başının oluşturduğu sinovyal bir eklem olup ön kolun rotasyon hareketlerinden sorumludur (Şekil 1). Ön kolun longitudinal rotasyon aksı proksimalde radius başının merkezi ile distalde ulnar foveayı birleştiren hat üzerindedir. DRUE'nin anatomik yapısı, eklem stabilitesini korurken hem ön kol rotasyonuna izin verir, hem de radyokarpal eklemden ön kol kemiklerine yük aktarımını sağlayabilmektedir. ${ }^{[1]}$ Sigmoid çentiğin sığ olması ve yarıçapının ulna başının yarıçapından \%50 daha büyük olması nedeniyle ön kol rotasyonu ve yük aktarımı sırasında ulna başı $1 \mathrm{~cm}$ kadar translase olabilir. ${ }^{[2]}$ Eklemi oluşturan kemik yapılar

\footnotetext{
- İletişim adresi: Prof. Dr. Kahraman Öztürk, Balta Limanı Hisar Cd. No: 62, 34470 Sarıyer, İstanbul Tel: 0532 - 4271798 e-posta: kahraman_ozturk@hotmail.com

- Geliș tarihi: 16 Mayıs $2021 \quad$ Kabul tarihi: 7 Haziran 2021
} 


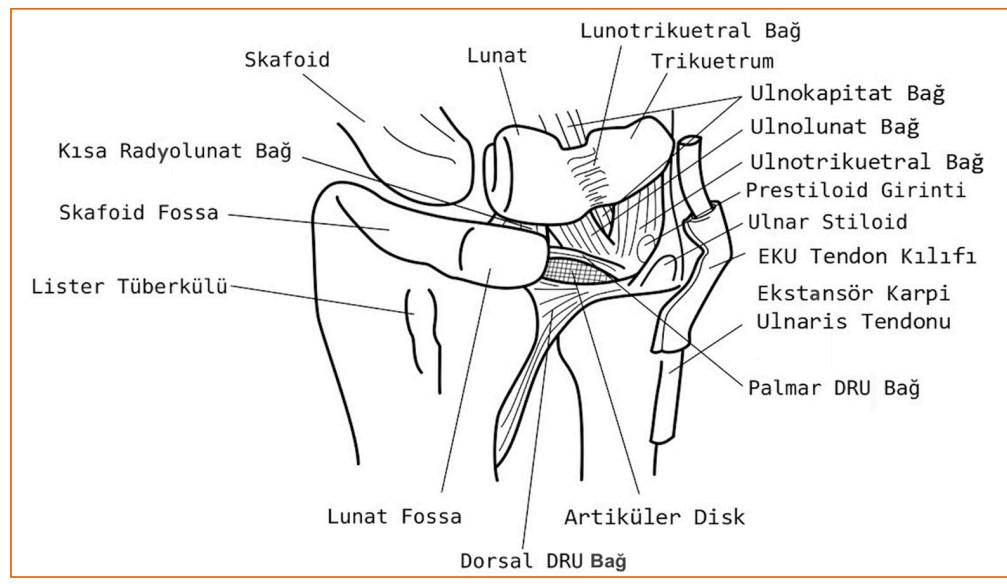

Şekil 1. Distal radyoulnar eklemi (DRUE) oluşturan anatomik yapıların şematik görünümü (EKU, ekstansör karpi ulnaris; DRU, distal radyoulnar).

arasındaki uyumsuzluk nedeniyle DRUE anatomik olarak stabilitesi zayıf bir eklemdir. ${ }^{[3]}$ Yapılan biyomekanik çalışmalarda kemik yapıların eklem stabilitesi üzerindeki etkilerinin \%20 civarında olduğu bildirilmiştir. ${ }^{[4]}$ Ön kol rotasyonunun en uç değerlerinde DRU eklemi oluşturan iki kemik arasındaki temasın eklem yüzey alanının \%10'u kadar olduğu gösterilmiştir. ${ }^{[5]}$ Sigmoid çentik sığ olsa da volar ve dorsal dudakları eklem stabilitesinin sağlanmasında önemlidir. Sigmoid çentiğin anatomik yapısındaki varyasyonları veya travma sonrası gelişebilecek yetmezliklerinin yapılan yumuşak doku rekonstrüksiyonları sonrası beklenen sonuçların alınamamasına neden olabileceği bildirilmiştir. ${ }^{[6]}$ Triangular fibrokartilaj kompleksinin (TFKK) anatomik yapısının tarifinden bu yana TFKK'nin volar ve dorsal radyoulnar bağlarının DRUE stabilitesinin sağlanmasında en önemli anatomik yapılar olduğu bilinmektedir. ${ }^{[7]}$ Pronator kuadratus kası, interosseöz membran (IOM), ekstansör karpi ulnaris (EKU) tendonu ve eklem kapsülü gibi çevre yumuşak dokuların bütünlüğündeki devamlılığın da eklem stabilitesinin sağlanmasında rol oynadığı bildirilmektedir. Yapılan kadavra çalışmalarında sadece DRU bağların ve triangular kıkırdağın sağlam olup diğer çevre yumuşak doku stabilizatörlerinin olmadığı durumlarda da DRUE stabilitesinin korunabildiği gösterilmiştir. ${ }^{[8]}$ Çevre yumuşak dokuların DRUE stabilitesinin sağlanmasında etkili olduğu bilinse de, her birinin ayrı ayrı etkisinin ne kadar olduğu tartışmalı bir konudur. Ciddi instabilite tablosunun ortaya çıkması için birden fazla anatomik yapının yaralanması gerektiği düşünülmektedir. ${ }^{[9]}$

Distal radyoulnar eklem instabilitesi, sık görülen, eklemi oluşturan veya çevreleyen anatomik yapılardaki bozukluklara bağı ıgelişen, tanısı ve tedavisi hekimler için zorlayıcı olabilecek bir durumdur. DRUE instabilitesi; primer, travma sonrası veya cerrahi sonrası instabilite olarak sınıflandırılabilmektedir. Bu sınıflamanın yanında, olgular şikayetlerin varlığına göre semptomatik veya asemptomatik olarak, oluş zamanına göre de akut veya kronik olarak, instabilitenin yönüne göre dorsal, volar veya çok yönlü instabilite olarak da sınıflandırılabilmektedir. ${ }^{[3]}$

Primer instabiliteler nadir görülürler. Özellikle, romatoid artrit gibi enflamatuvar hastalıklara bağlı olarak gelişirler. Primer instabilitenin bir diğer sebebi de EhlerDanlos sendromu gibi bağ dokusu hastalıklarıdır. ${ }^{[10]}$

Distal radyoulnar eklem instabiliteleri travma sonrası sıklıkla görülmekte olup en sık radius distal uç kırıklarından (RDUK) sonra görülmektedir. ${ }^{[11]}$ RDUK sonrası DRUE instabilitesi görülme insidansının \%10-19 olduğu bildirilmiştir. ${ }^{[12]}$ Travma sonrası gelişen DRUE instabilitesinin diğer sebepleri olarak TFKK yaralanması, EKU tendonu instabilitesi, IOM yaralanması, eklem kıkırdağında hasarlanma veya ön kol kemiklerinin yanlış kaynamaları sıralanabilir.

Distal radyoulnar eklem instabilitesi tanısı koymak, bulguların her hastada belirgin olmaması ve genel kabul görmüş tanı kriterlerinin olmaması nedeniyle hekimler için zorlayıcıdır. Tanının konulması ve uygun tedavinin seçiminde instabiliteye neden olan faktörlerin tam olarak değerlendirilmesi ve anlaşılması önemlidir.

Hastalarda açık el üzerine düşme sonrası başlayan ulnar taraflı el bileği ağrısı şikâyeti mevcuttur. Ağrı, özellikle zorlayıcı ön kol rotasyonu sırasında artmaktadır. Hastaların diğer başvuru şikâyetleri ulna başının cilt altında belirginleşmesi, ön kol rotasyon hareketlerinde kısıtlılık ve kavrama gücünde azalmadır. 


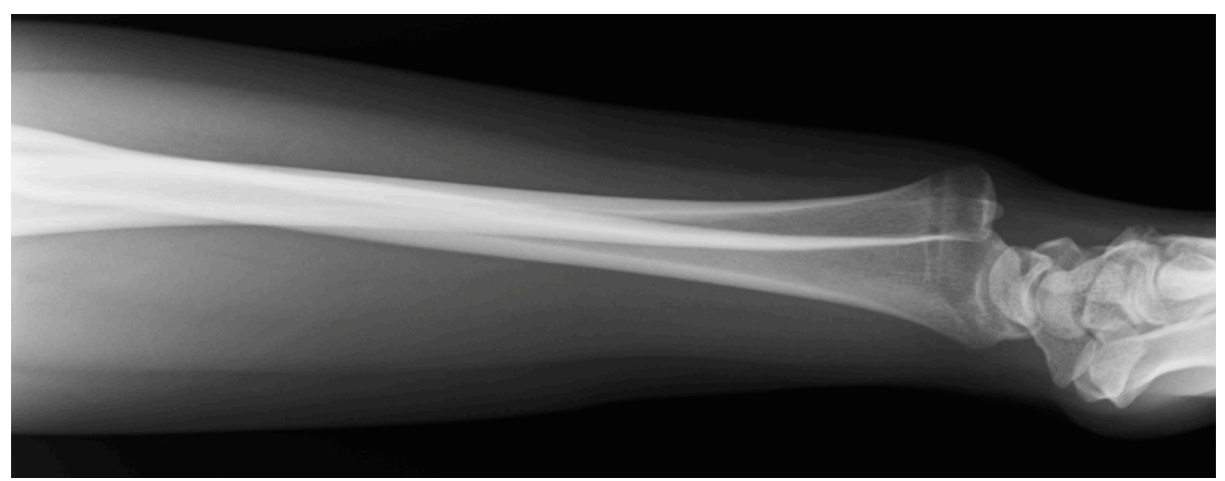

Şekil 2. El bileği yan radyografisinde ulna başının dorsale çıkı̆̆ı görülmektedir.

Ön kol rotasyonu sırasında ulna başı sabit olup hareketli birim radius ve karpal kemikler olsa da instabilitenin yönü genellikle ulna başının yerleşimine göre tarif edilmektedir. İzole DRUE çıkıkları çoğunlukla dorsale doğru olup el bileği ekstansiyondayken aşırı pronasyona zorlanması sonrası gelişirler. Volar çıkıklar, ön kol supinasyondayken ulnar taraftan gelen şiddetli direkt darbe sonucu ortaya çıkmaktadır. İzole çıkıklarda ön kol rotasyonu ile ulna başının redüksiyonu ve dislokasyonu palpe edilebilir. Dorsal çıkıklarda ulna başı dorsalde belirginken, volar çıkıklarda el bileği dorsalinde gamzeleşme gözlenebilir. ${ }^{[3]}$

Fizik muayene, iki taraf karşılaştırmalı olarak ve şikâyetin olmadığı taraftan başlanarak yapılmalıdır. Her iki taraf el bileğinin pasif ve aktif eklem hareket açıklığı değerlendirilmelidir.

Distal radyoulnar eklem instabilitesini değerlendirmede en etkili testlerden biri de ballotman testidir. ${ }^{[13]}$ Ön kol nötralde, supinasyonda ve pronasyondayken radius bir elle sabit tutulurken diğer elle ulna ön-arka planda translase edilir. Muayene sağlam tarafla karşılaştırmalı olarak yapılmalıdır. Ulna başının karşı tarafa göre artmış translasyonu DRUE instabilitesi olarak kabul edilir. DRU eklemin sekonder stabilizatörleri olan EKU ve pronator kuadratus kaslarında muayene sırasında gelişen koruyucu kasılmaların muayenenin etkinliğini kısıtlayarak yalancı negatif sonuca neden olması dolayısıyla testin cerrahi sırasında hasta anestezi altındayken tekrarlanması önerilmektedir. Tanıda en güvenilir fizik muayene yönteminin ballotman testi olduğu bildirilmektedir. ${ }^{[14]}$ Ulnar taraflı el bileği ağrısının değerlendirilmesinde yararlı testlerden biri de fovea testidir. Fovea testinde, ulna stiloidi ile fleksör karpi ulnaris (FKU) tendonu arasındaki bölgeye parmak ile bası uygulanması sonrası hastada ağrının ortaya çıkması pozitif bulgu olarak değerlendirilir ve distal radyoulnar bağların foveal yapışma yeri yırtıklarında duyarlılığının \%95, özgüllüğünün \%87 olduğu bildirilmiştir. ${ }^{[15]}$ Dirsek $90^{\circ}$ fleksiyonda, ön kol pronasyonda ve el bileği masa üstünde istirahatteyken ulna başına volare doğru bası uygulanarak yapılan piyano tuşu testinde karşı tarafa göre laksitenin fazla olması TFKK yaralanması lehine bir bulgudur. ${ }^{[16]}$

Distal radyoulnar eklem instabilitesinin radyolojik değerlendirilmesinde ilk olarak postero-anterior (PA) ve yan el bileği grafileri istenilmelidir. Direkt grafiler ulnar varyansta değişikliğe neden olabilecek radius ve ulnanın yanlış kaynamalarının değerlendirilmesinde önemlidir. Distal radyoulnar bağların yapışma yeri olan ulna stiloidi tabanını veya distal radius dorsoulnarını etkileyen kırıklar direkt grafilerde değerlendirilerek eklem stabilitesi hakkında fikir edinilebilmektedir. PA grafilerde radyoulnar mesafenin $3 \mathrm{~mm}$ 'den fazla olması, yan grafilerde radius dorsali ile ulna dorsali arasındaki radyoulnar mesafenin $6 \mathrm{~mm}$ 'den fazla olması DRUE instabilitesi lehine bulgulardır (Şekil 2). ${ }^{[17,18]}$ Ayrıca direkt grafilerde DRU artrozu varlığı ve derecesi değerlendirilebilmektedir. Distal radyoulnar eklem uyumunu değerlendirmede en etkili yöntem bilgisayarlı tomografidir (BT'dir). Bu değerlendirmenin Lister tüberkülünden geçen aksiyel kesitlerden yapılması önerilmektedir. Distal radyoulnar eklem subluksasyonlarını ve çıkıklarını değerlendirmek için çeşitli yöntemler tarif edilmişse de en duyarlısının epicenter yöntemi olduğu bildirilmektedir. ${ }^{[19]}$ Manyetik rezonans (MR) görüntüleme, DRUE stabilitesinden sorumlu çevre yumuşak dokuların ve eklem kıkırdağının durumunu değerlendirmede etkili bir yöntemdir. İnce kesit MR görüntüleme, TFKK santralindeki yırtıkların tanısında yüksek duyarlılık ve özgüllüğe sahipken periferik yırtıklarda duyarlılık ve özgüllüğü düşmektedir (Şekil 3). ${ }^{[20]}$ Distal radyoulnar eklem instabilitesinin değerlendirilmesinde ön kol supinasyonda ve pronasyonda el bileği MR görüntülemesinin tanıda yararlı olacağı bildirilmiştir. ${ }^{[21]}$

Distal radyoulnar eklem instabilitesi olan hastalarda eşlik edebilecek DRUE artrozu, ulnar impaksiyon 


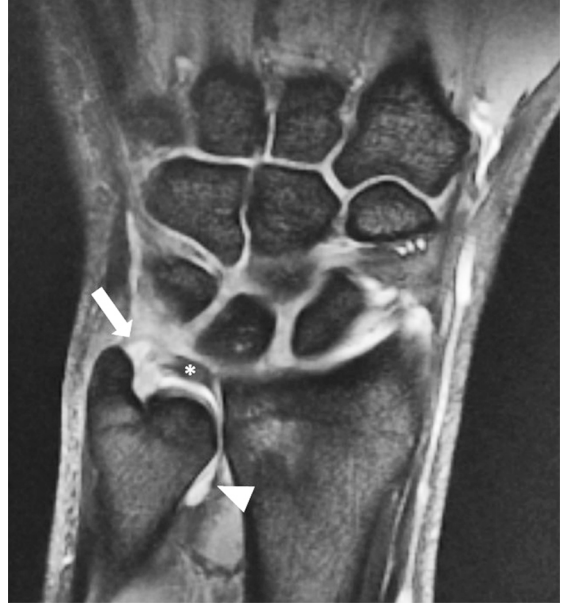

Şekil 3. Yağ baskılamalı T2 ağılıklı koronal manyetik rezonans görüntüleme sekanslarında triangular fibrokartilaj kompleksinin (TFKK) (asterisk) ulna stiloidi ve ulnar foveaya tutunma bölgelerindeki sinyal artışı (beyaz ok) tam kat yırtık olarak yorumlanmaktadır. Distal radyoulnar eklemdeki artmış sıvı sinyalleri de yırtı̆̆ını desteklemektedir (ok başı).

sendromu, EKU tendiniti, EKU tendonu subluksasyonu, ulnokarpal bağ yaralanmaları gibi patolojiler tanının konulması ve tedavinin planlamasında göz önünde tutulmalıdır. Diğer patolojilerin eşlik ettiği instabilitelerde sorunun sadece bir bileşeninin tedavi edilmesi ile başarılı sonuçlar elde etmek mümkün olmayacaktır. Tedavi yönteminin seçiminde hastaya ait faktörler, cerrahın tecrübesi ve sağlık biriminin şartları göz önünde tutulmalıdır.

Akut dönemde tanı konulan ve redükte edilebilen DRUE çıkıkları konservatif yöntemlerle tedavi edilebilir. Eklem uygun manevralarla redükte edilerek dorsal çıkıklarda ön kol supinasyonda, volar çıkıklarda ön kol pronasyonda olacak şekilde altı hafta dirsek üstü alçı uygulanmalıdır (Şekil 4). Aktivite düzeyi düşük kronik DRUE instabilitesi olan hastalarda fonksiyonel atelleme tedavinin ilk basamağında kullanılabilmektedir. ${ }^{[22]}$
Kronik, semptomatik DRUE instabilitesi olan hastalarda pozitif ballotman testi ve fovea bulgusu varlığında üç aylık konservatif tedaviye rağmen şikâyetlerde gerileme olmuyorsa cerrahi tedavi düşünülmelidir. Distal radyoulnar eklem anatomisi ve biyomekaniği üzerine yapılan çalışmaların ışığında eklem instabilitesinin tedavisi tenodez gibi anatomik olmayan indirekt yöntemlerden diz ve dirsekte de başarı ile uygulanan bağların anatomik rekonstrüksiyonu gibi yöntemlere doğru evrilmiştir.

Distal radius yanlış kaynamaları sonrası gelişen instabilitelerde bağ rekonstrüksiyonu uygulanması bazı durumlarda gerekli olmayabilir. Düzeltici osteotomi ile dizilimin düzeltilmesi sonrası instabilite düzelebilmektedir. Distal radyoulnar eklem instabilitesinin en sık nedeni radius yanlış kaynamaları olsa da kabul edilebilir sınırlarda radius diziliminin sağlandığı bazı kırıklı hastalarda da eklemde instabilite gelişebilmektedir. Bu durum DRU bağlardaki yaralanmanın eklem stabilitesinin bozulması üzerinde etkili olduğunu göstermektedir. Bağ rekonstrüksiyonları, fonksiyonel yetmezlik yanlış kaynamadan ziyade dinamik stabilizatörlerin yaralanmasına bağlı gelişmişse gerekmektedir. Radius yanlış kaynamaları sonrası gelişen DRUE instabilitelerinde düzeltici osteotomiler ile bağ rekonstrüksiyonu eş zamanlı olarak uygulanabilmektedir.

Yaralanmanın üzerinden geçen zamandan bağımsız olarak DRU bağların primer olarak tamir edilmesi için tüm çaba harcanmalıdır. Distal radyoulnar bağ rekonstrüksiyonları, primer tamirin mümkün olmadığı olgularda uygulanmalıdır. Ameliyat öncesi değerlendirmelerde bağların primer tamire uygunluğuna karar vermek güç olmakla birlikte, yaralanmanın üzerinden geçen zaman arttıkça bağ rekonstrüksiyonu ihtiyacı o oranda artmaktadır. ${ }^{[23]}$

Kronik DRUE instabilitesinin tedavisinde ilk dönemlerde anatomik olmayan rekonstrüksiyon yöntemleri kullanılmıştır. Bu yöntemler kısaca radius ve ulnanın tendon otogreftleri ile birbirine askı yöntemleri ile tespit edilmesi, distal ulnanın tenodez ile stabilize edilmesi

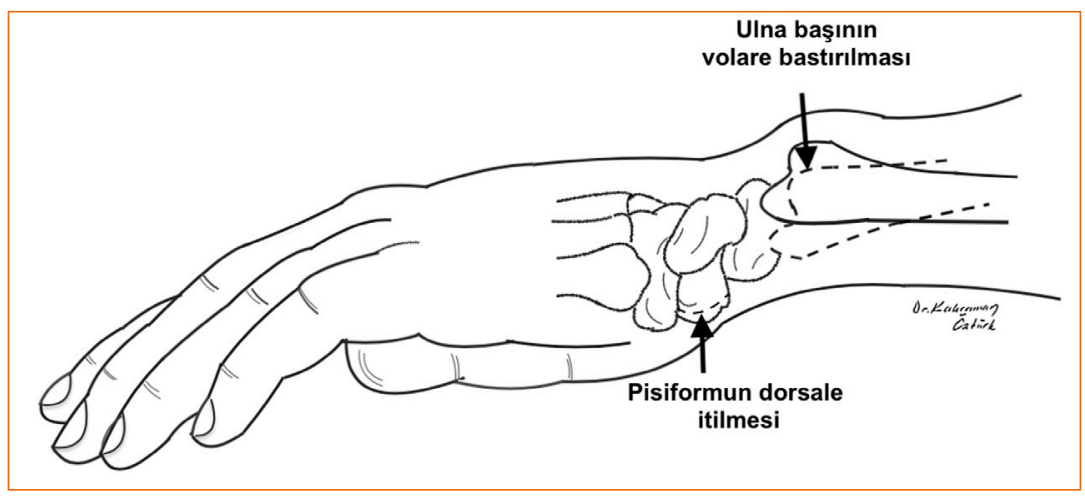

Şekil 4. Karpal supinasyonun eşlik ettiği distal radyoulnar eklemin dorsal çıkığı. Ulna başının volare bastırılması ve pisiformun dorsale itilmesi ile uygulanan redüksiyon manevrası. 
ve tendon otogreftleri ile ulnokarpal bağın rekonstrükte edilmesi olarak özetlenebilmektedir. Yapılan biyomekanik çalışmalar anatomik olmayan rekonstrüksiyon yöntemleri ile DRUE stabilitesinin ve kinematiğinin normale yakın olarak elde edilemediğini göstermiştir. ${ }^{[24]}$

Fulkerson ve Watson tarafindan tarif edilen anatomik olmayan DRU bağ rekonstrüksiyonu yönteminde ulna boynu seviyesinde ön-arka yönünde radiusun ulnar tarafindan açılan kemik tünelden geçirilen tendon greftinin iki bacağı ulna etrafına sarılır. Greftin sarılmasıyla sağlanan rekonstrüksiyonun mimarisinin ulnanın dorsal, volar ve lateral subluksasyonunu engellediği bildirilmiştir. Yazarlar, bu teknik ile ulna başı rezeksiyonu ihtiyacının ortadan kaldırılabileceği veya geciktirilebileceği sonucuna varmışlardır. ${ }^{[25]}$ Fulkerson ve Watson tekniği ile semptomlarda gerileme görülse de rekonstrüksiyonun tasarımı biyomekanik olarak belirgin sorunlar içermektedir. Ön kolun rotasyon aksının foveadan geçtiği düşünüldügüunde tendon greftinin ulna boynuna sarılması nedeniyle rotasyon aksı değişecektir ve bunun sonucunda ön kol rotasyonunda kısıtlılık gelişecektir. ${ }^{[24]}$

Distal radyoulnar eklem instabilitesinin tedavisi için tarif edilen bir diğer teknik olan tenodezlerde ise indirekt yöntemlerle eklem stabilitesinin sağlanmasına çaIışılmıştır. FKU veya EKU tendonunun kullanıldığı anatomik olmayan yöntemler tanımlanmıştır. ${ }^{[26,27]}$ Geniş bir insizyon ve çoklu transosseöz tüneller gerektiren tenodez yöntemleri ile yeterli eklem stabilitesinin elde edilemediği ve eklem hareketlerinde kısıtıılık geliştiği bildirilmiştir. ${ }^{[28,29]}$

Filius ve ark., ekstansör retinakulumdan radyal tabanlı alınan bir slip ile bağın rekonstrükte edildiği ve aynı seansta kapsüler plikasyon uygulanan bir yöntem tarif etmişlerdir. Yazarlar, bu yöntemin diğer anatomik DRU bağ rekonstrüksiyon yöntemlerine göre daha kolay uygulanabilir ve daha az invaziv olduğunu bildirmişlerdir. ${ }^{[30]}$ Eklem kapsülü, pronasyon ve supinasyonun uç noktalarında eklem stabilitesinin sağlanmasında görev almaktadır. Kronik instabilitelerde sadece eklem kapsülünün tamir edilmesi yeterli stabilitenin sağlanmasına yetmemektedir. ${ }^{[31]}$ Bu yöntemde, uygulanan bağ rekonstrüksiyonu ve kapsül plikasyonu ile anatomik bağ rekonstrüksiyonuna yakın sonuçlar elde edildiği bildirilmiştir. Otuz sekiz hastanın sonuçlarını bildirdikleri yazılarında, 36 hastada stabil bir DRUE elde ettiklerini, ameliyat sonrası dönemde el bileği radyal-ulnar deviasyon hareketlerinin ön kol pronasyonsupinasyon hareketlerine göre daha fazla etkilendiğini belirtmişlerdir. ${ }^{[30]}$

Adams ve Berger, DRUE instabilitesi olup eklem kıkırdağı sağlam ve diğer el bilek bağları fonksiyonel olan hastalarda anatomik DRU bağ rekonstrüksiyonunun etkili bir tedavi yöntemi olduğunu bildirmişlerdir (Şekil 5). Anatomik bağ rekonstrüksiyonu uyguladıkları 14 hastanın 12'sinde eklem stabilitesinin sağlandığını ve semptomların gerilediğini bildirmişlerdir. ${ }^{[32]}$ Cerrahi teknikte el bileği dorsalinden 5. ve 6. ekstansör kompartman arasından $4 \mathrm{~cm}$ 'lik kesi ile girilerek DRUE kapsülü proksimal ve ulnar tarafa doğru ekarte edilir. Triangular fibrokartilaj kompleksi, tamire uygunluğu ve iyileşme potansiyeli açısından değerlendirilir. Triangular fibrokartilaj kompleksi, tamir edilemeyecek kadar dejenereyse veya tamir edildiğinde eklem stabilitesini sağlayacak kadar sağlam değilse bağ rekonstrüksiyonu işlemi uygulanmalıdır. Dejenere TFKK kalıntıları debride edilmeli, volar DRU bağın kalıntıları ve ulnokarpal bağlar mümkün olduğunca korunmalıdır. Ulnokarpal eklem stabilitesinin korunması amacıyla EKU tendon kılıfi disseke edilmemelidir. Radiustaki kemik tünel floroskopi kontrolünde, lunat fossanın birkaç $\mathrm{mm}$ proksimalinden ve sigmoid çentiğin birkaç $\mathrm{mm}$ radyalinden açılır. Daha sonra, ulnar foveadan ulna boynuna doğru olacak şekilde ulnar kemik tüneli açılır. El bileği volarinde nörovasküler yapılar korunarak radiustaki tünelin volarine ulaşılır. Radius volarinden dorsaline doğru ilerletilen tendon greftinin iki bacağı ulnar tünelden geçirilir. Tendon greftinin bir bacağı ulna boynu etrafından döndürülerek uygun

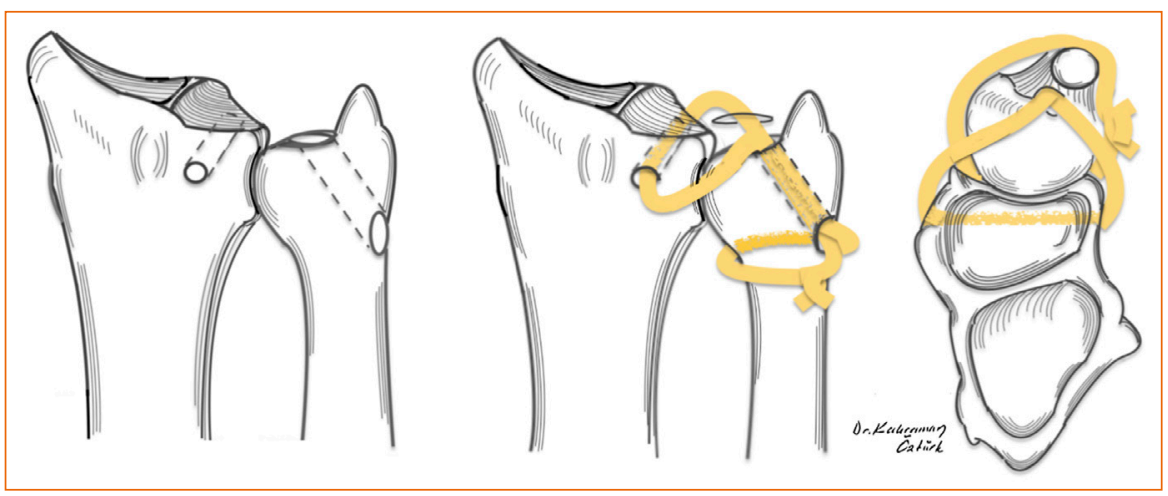

Şekil 5. Anatomik distal radyoulnar bağ rekonstrüksiyonu. Distal radiusun ulnar tarafinda dorsal ve volar yönde açılan tünel ve ulnar foveada açılan kemik tünellerden geçirilen tendon grefti uygun gerginlikte ulna boynu seviyesinde tespit edilir. 

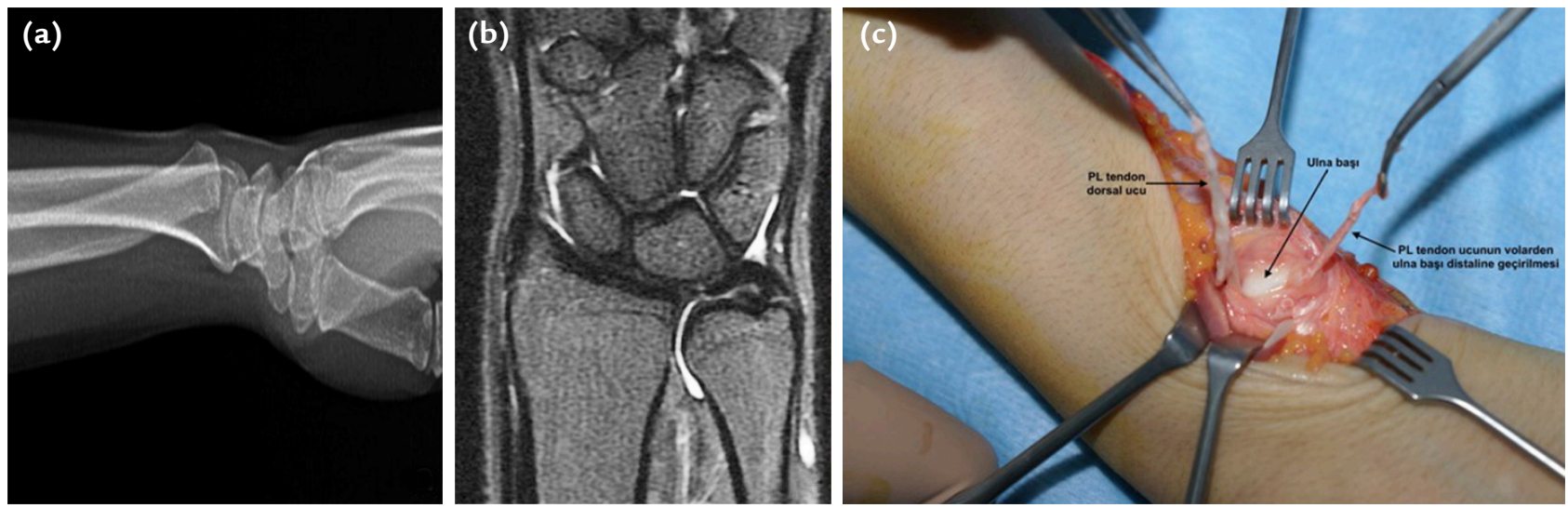

Şekil 6. a-e. Geç dönemde radyoulnar eklemde instabilite şikâyeti ile başvuran hastanın yan radyografisinde ulnanın dorsale çıkığı (a) görülmektedir. Triangular fibrokartilaj kompleksinin (TFKK) tam kat yırtığını gösteren koronal T2 manyetik rezonans (MR) kesiti

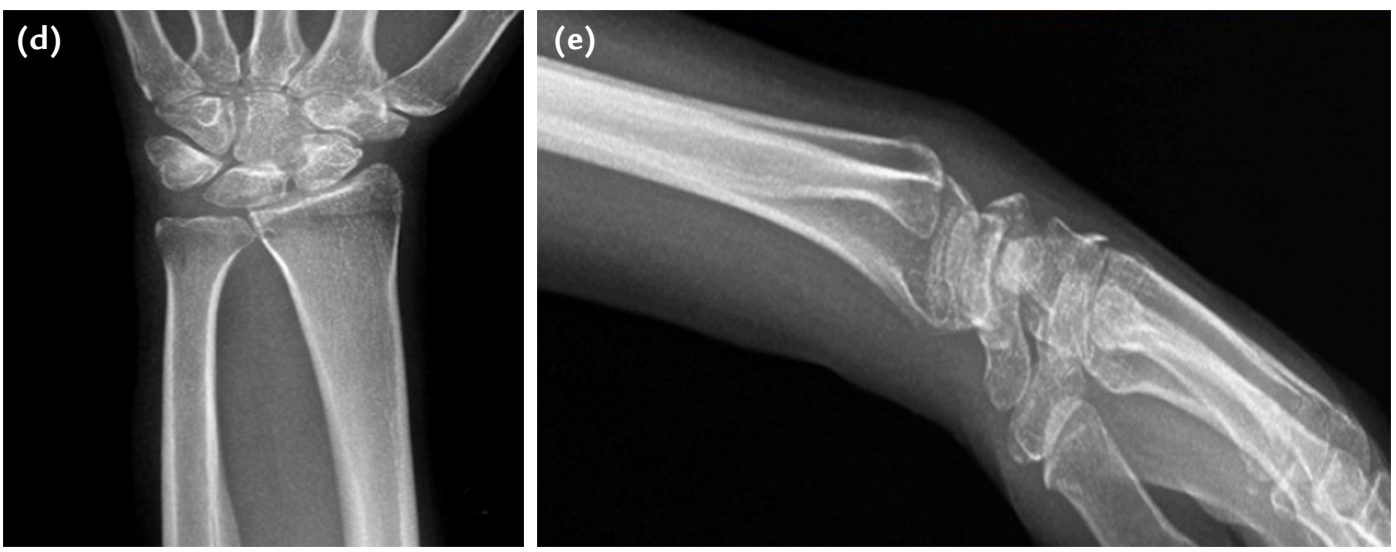
(b). Palmaris longus (PL) tendonu ile açık radyoulnar bağ rekonstrüksiyonu uygulanan hastada tendonun bir ucu radius dorsalinde iken diğer ucunun radius volarine ve sonra volarden dorsale ulna distaline geçirildiği (c) görülmektedir. Ameliyat sonrası arka ön (d) ve yan radyografide (e) eklemin redükte olduğu görülmektedir.

gerginlikte diğer bacağa emilmeyen dikişle dikilir (Şekil $6)$. Rezidüel instabilite varsa, hasta obez veya uyumsuzsa ulnadan radiusa gönderilen bir adet Kirschner teli (K-teli) ile rekonstrüksiyon güvenceye alınabilir. ${ }^{[33]}$ Seo ve ark., çalışmalarında anatomik bağ rekonstrüksiyonu sonrası 16 hastanın $15^{\prime}$ 'inde eklem stabilitesinin sağlandığını, ön kol rotasyon hareketlerinde ağrı olmadığını, kavrama kuvvetinin arttı̆̆ını, tatmin edici fonksiyonel sonuçlar elde ettiklerini ve hastaların ameliyat öncesi eklem hareket açıklıklarının korunduğunu bildirmişlerdir. ${ }^{[29]}$ Genel bağ laksitesi olan hastalarda veya kollajen hastalıkları (Ehler-Danlos sendromu, Marfan sendromu) olanlarda bağ rekonstrüksiyonunun göreceli kontrendike olduğu unutulmamalıdır. ${ }^{[32]}$

ilk olarak Sanders tarafindan tarif edilen ama yayımlanmayan volar ve dorsal radyoulnar (RU) bağların rekonstrüksiyonu için iki-bacaklı tendon otogrefti ile anatomik bağ rekonstrüksiyonu yöntemi daha sonra Hearon ve ark. tarafindan modifiye edilmiştir. Tendon greftinin ortası ulnar foveada açılan bir kemik tünelde tespit edilmişken, greftin bir bacağı radyalde volar el bileği kapsülüne, diğer bacağı ise dorsal retinakuluma tespit edilmiştir. ${ }^{[34]}$ Plaklama sonrası uygun dizilimle kaynamış RDUK sonrası sebat eden DRUE instabilitesi olan hastalarda, plak yerleşimine bağlı olarak Adams tekniğinin uygulanabilmesi amacıyla radyal tünelin açılması cerrah için zorlayıcı olabilmektedir. Bu durumlarda Sanders tekniğinin iyi bir alternatif olabileceği unutulmamalıdır.

Son dönemlerde, birçok el bileği patolojisinin tanı ve tedavisinde etkin bir şekilde uygulanan artroskopinin eklem içinin değerlendirilmesindeki üstünlüğü ve daha az morbiditeye yol açması belirgin avantajlarını oluşturmaktadır. Artroskopik destekli bağ rekonstrüksiyonu ile cerrahi travmanın azaltılması sonucu ameliyat sonrası ağrının azalacağı ve bunun rehabilitasyonu olumlu yönde etkileyeceği öngörülmektedir. Ayrıca eklem içinin daha iyi görüntülenmesiyle rekonstrüksiyon uygunluğunun ve bunun sonucunda fonksiyonel sonuçların daha iyi olacağı öngörülmektedir. ${ }^{[35]}$ Artroskopi destekli DRU bağ rekonstrüksiyonu, uzunluğu cerrahın tecrübesine göre değişmekle birlikte birkaç mini insizyonla uygulanabilmektedir. Cerrahi işlemde öncelikle el bileğine 4-7 kg aksiyel traksiyon uygulanır. El bileği volarinden 

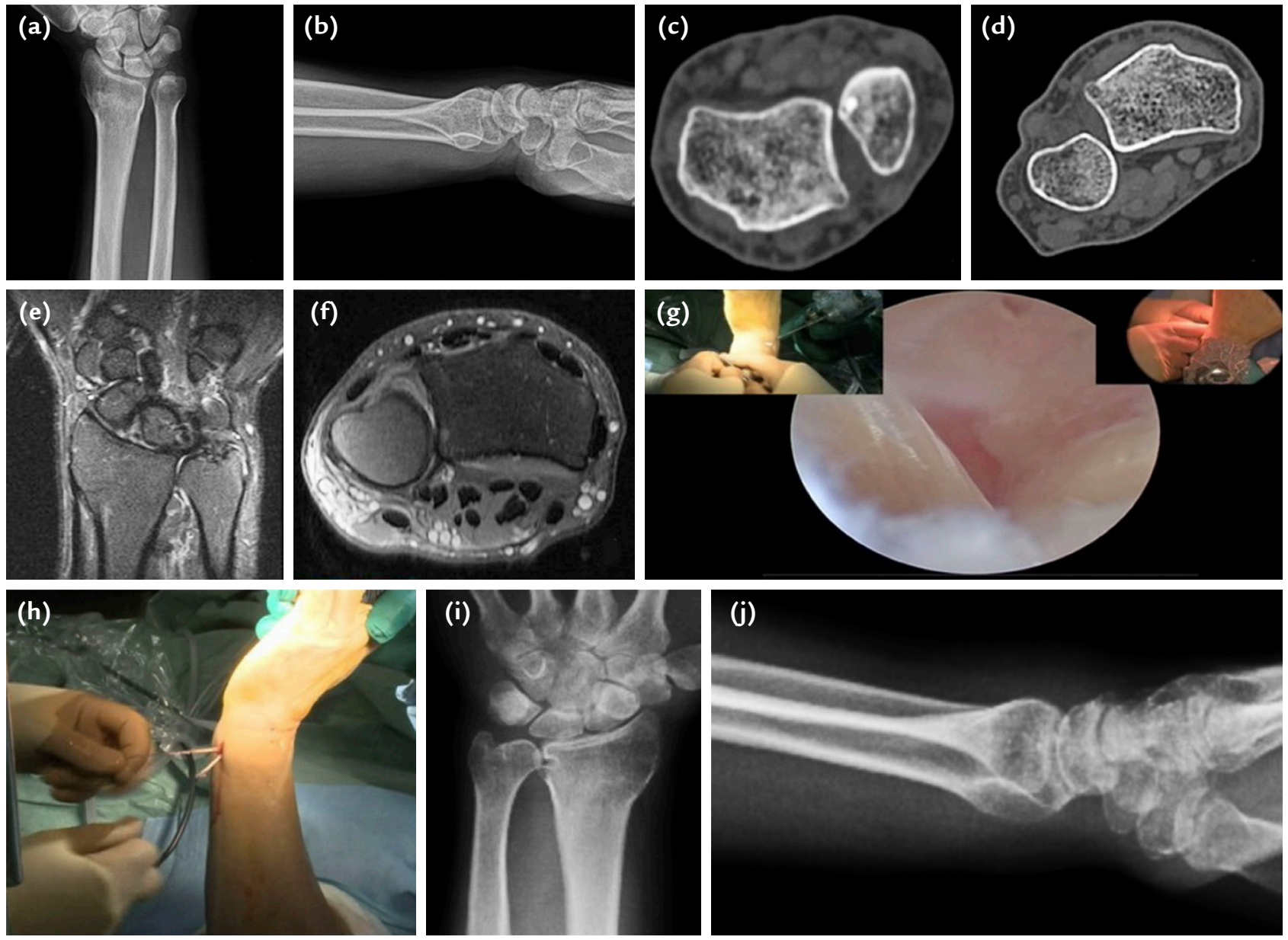

Şekil 7. a-j. Distal radyoulnar eklem instabilitesi olan olgunun el bileği ön arka radyografisinde radyoulnar aralıkta açılma (a) ve yan grafide ulna başının volare kaydığı (b) görülmektedir. Ulna başının supinasyonda (c) ve pronasyonda (d) volare sublukse olduğu bilgisayarlı tomografi (BT) kesitleri. T2 manyetik rezonans (MR) koronal kesitte tam kat triangular fibrokartilaj kompleksi (TFKK) yırtığı (e) ve aksiyel kesitte ulna başının volare subluksasyonu ( $f$ ) izlenmektedir. El bilek artroskopisinde palmaris longus tendon greftinin ulna stiloid tabanında açılan tünelden geçirilmesi (g) ve ulnar tünelden çıkarılması (h) görülmektedir. Birinci yıl kontrol arka ön radyografisinde radyoulnar eklem aralığının kapandığı (i) ve yan radyografide (j) ulna distalinin yerinde olduğu görülmektedir.

radiusun ulnar köşesini görebilecek şekilde mini insizyon uygulanır. Volardeki kesinin tam karşısında el bileği dorsalinden radiusun ulnar ve distal köşesini görecek ikinci bir mini insizyon uygulanır. Median sinir ve çevre yumuşak dokular korunarak radiusun ulnar tarafindan bir adet kılavuz teli gönderilir; 2,5 mm'lik kanüle drill ile radiustaki kemik tünel açlır ve tendon grefti dorsalden volare doğru ilerletilir. Daha sonraki aşamada 3-4 portali açılarak artroskopik olarak TFKK değerlendirilir. 6R portali işlem portali olarak kullanılarak TFKK debride edilir. Ön kol supinasyona alınarak $6 U$ portalinin hemen proksimalinden $2 \mathrm{~cm}$ 'lik kesi uygulanarak ulnanın medialindeki yumuşak dokular eleve edilir. Bu işlem uygulanırken ulnar sinirin dorsal duyu dalı korunmalıdır. Oblik olarak proksimalden distale doğru ulnar fovea hedeflenerek bir adet kılavuz teli gönderilir. Kılavuz telinin foveadan çıkış yeri artroskopik olarak kontrol edilir; 3,2 mm'lik kanüle drill ile ulnar kemik tüneli açılır. Bir klemp yardımı ile tendon greftinin iki ucu ulnar kemik tünelden geçirilir. El bileği traksiyonu gevşetilerek greft uygun gerginlikteyken bir adet interferans vidası ile tespit edilir (Şekil 7). ${ }^{[36]}$ Luchetti ve Atzei, ortalama 68 ay takip süresi olan artroskopi destekli DRU bağ rekonstrüksiyonu uygulanan 11 hastanın sonuçlarını bildirdikleri çalışmalarında, 10 hastada klinik olarak stabil bir DRUE elde ettiklerini belirtmişlerdir. Hastaların ağrılarında belirgin azalma olurken kavrama kuwetlerinin arttığını, ameliyat sonrası dönemde hastaların ön kol rotasyon açıklığının korunduğunu bildirmişlerdir. ${ }^{[35]}$ 
Distal radyoulnar eklem instabilitesi tedavisinde stabil, ağrısız ve tam eklem hareket açıklığına sahip bir eklem elde edilmesi amaçlanmaktadır. Yapılan çalışmaların sonuçları değerlendirildiğinde TFKK'nin primer olarak tamir edilemediği durumlarda ulna başı korunarak DRU bağların rekonstrükte edilmesi ile tedavi amaçlarına en yakın sonuçların elde edilebileceğini düşünmekteyiz.

\section{KAYNAKLAR}

1. Kleinman WB. Stability of the distal radioulna joint: biomechanics, pathophysiology, physical diagnosis, and restoration of function what we have learned in 25 years. $J$ Hand Surg Am 2007;32(7):1086-106. Crossref

2. Gupta R, Allaire RB, Fornalski S, Osterman AL, Lee TQ. Kinematic analysis of the distal radioulnar joint after a simulated progressive ulnar-sided wrist injury. J Hand Surg Am 2002;27(5):854-62. Crossref

3. Szabo RM. Distal radioulnar joint instability. J Bone Joint Surg Am 2006;88(4):884-94. Crossref

4. Carlsen BT, Dennison DG, Moran SL. Acute dislocations of the distal radioulnar joint and distal ulna fractures. Hand Clin 2010;26(4):503-16. Crossref

5. Ekenstam FAF, Hagert CG. Anatomical studies on the geometry and stability of the distal radio ulnar joint. Scand J Plast Reconstr Surg 1985;19(1):17-25. Crossref

6. Tolat AR, Stanley JK, Trail IA. A cadaveric study of the anatomy and stability of the distal radioulnar joint in the coronal and transverse planes. J Hand Surg Br 1996;21(5):587-94. Crossref

7. Palmer AK, Werner FW. The triangular fibrocartilage complex of the wrist--anatomy and function. J Hand Surg Am 1981;6(2):153-62. Crossref

8. Gofton WT, Gordon KD, Dunning CE, Johnson JA, King GJ. Soft-tissue stabilizers of the distal radioulnar joint: an in vitro kinematic study. J Hand Surg Am 2004;29(3):423-31. Crossref

9. Stuart PR, Berger RA, Linscheid RL, An KN. The dorsopalmar stability of the distal radioulnar joint. J Hand Surg Am 2000;25(4):689-99. Crossref

10. Zimmerman RM, Jupiter JB. Instability of the distal radioulnar joint. J Hand Surg Br 2014;39(7):727-38. Crossref

11. Mulford JS, Axelrod TS. Traumatic injuries of the distal radioulnar joint. Hand Clin 2010;26(1):155-63. Crossref

12. Kazemian GH, Bakhshi $H$, Lilley M, Moghaddam MET, Omidian MM, Safdari F, Mohammadpour I. DRUJ instability after distal radius fracture: a comparison between cases with and without ulnar styloid fracture. Int J Surg 2011;9(8):648-51. Crossref

13. Moriya T, Aoki M, Iba K, Ozasa Y, Wada T, Yamashita T. Effect of triangular ligament tears on distal radioulnar joint instability and evaluation of three clinical tests: a biomechanical study. J Hand Surg Br 2009;34(2):219-23. Crossref

14. Huang JI, Hanel DP. Anatomy and biomechanics of the distal radioulnar joint. Hand Clin 2012;28(2):157-63. Crossref

15. Tay SC, Tomita K, Berger RA. The "ulnar fovea sign" for defining ulnar wrist pain: an analysis of sensitivity and specificity. J Hand Surg Am 2007;32(4):438-44. Crossref

16. Young D, Papp S, Giachino A. Physical examination of the wrist. Orthop Clin North Am 2007;38(2):149-65. Crossref

17. Nakamura R, Horii E, Imaeda T, Tsunoda K, Nakao E. Distal radioulnar joint subluxation and dislocation diagnosed by standard roentgenography. Skeletal Radiol 1995;24(2):91-4. Crossref

18. lida A, Omokawa S, Akahane M, Kawamura K, Takayama K, Tanaka Y. Distal radioulnar joint stress radiography for detecting radioulnar ligament injury. J Hand Surg Am 2012;37(5):968-74. Crossref
19. Nakamura R, Horii E, Imaeda T, Nakao E. Criteria for diagnosing distal radioulnar joint subluxation by computed tomography. Skeletal Radiol 1996;25(7):649-53. Crossref

20. Potter HG, Asnis-Ernberg L, Weiland AJ, Hotchkiss RN, Peterson MG, McCormack RR Jr. The utility of highresolution magnetic resonance imaging in the evaluation of the triangular fibrocartilage complex of the wrist. J Bone Joint Surg Am 1997;79(11):1675-84. Crossref

21. Haims $A H$, Schweitzer ME, Morrison WB, Deely $D$, Lange R, Osterman AL, Bednar JM, Taras JS, Culp RW. Limitations of MR imaging in the diagnosis of peripheral tears of the triangular fibrocartilage of the wrist. AJR Am J Roentgenol 2002;178(2):419-22. Crossref

22. Millard GM, Budoff JE, Paravic V, Noble PC. Functional bracing for distal radioulnar joint instability. J Hand Surg Am 2002;27(6):972-77. Crossref

23. Faucher GK, Zimmerman RM, Zimmerman NB. Instability and arthritis of the distal radioulnar joint: A critical analysis review. JBJS Rev 2016;4(12):e3. Crossref

24. Petersen MS, Adams BD. Biomechanical evaluation of distal radioulnar reconstructions. J Hand Surg Am 1993;18(2):32834. Crossref

25. Fulkerson JP, Watson HK. Congenital anterior subluxation of the distal ulna. A case report. Clin Orthop Relat Res 1978;(131):179-82. Crossref

26. Breen TF, Jupiter JB. Extensor carpi ulnaris and flexor carpi ulnaris tenodesis of the unstable distal ulna. J Hand Surg Am 1989;14(4):612-17. Crossref

27. Tsai TM, Stilwell JH. Repair of chronic subluxation of the distal radioulnar joint (ulnar dorsal) using flexor carpi ulnaris tendon. J Hand Surg Br 1984;9(3):289-94. Crossref

28. Gofton WT, Gordon KD, Dunning CE, Johnson JA, King GJW. Comparison of distal radioulnar joint reconstructions using an active joint motion simulator. J Hand Surg Am 2005;30(4):733-42. Crossref

29. Seo KN, Park MJ, Kang HJ. Anatomic reconstruction of the distal radioulnar ligament for posttraumatic distal radioulnar joint instability. Clin Orthop Surg 2009;1(3):138-45. Crossref

30. Filius A, Zuidam JM, Jaquet JB, Slijper HP, Coert JH. Modification of the use of the extensor retinaculum for reducible distal radioulnar joint instability: technique and results. J Hand Surg Br 2017;42(8):839-45. Crossref

31. Watanabe H, Berger RA, An KN, Berglund LJ, Zobitz ME. Stability of the distal radioulnar joint contributed by the joint capsule. J Hand Surg Am 2004;29(6):1114-20. Crossref

32. Adams BD, Berger RA. An anatomic reconstruction of the distal radioulnar ligaments for posttraumatic distal radioulnar joint instability. J Hand Surg Am 2002;27(2):243-51. Crossref

33. Adams BD. Anatomic Reconstruction of the Distal Radioulnar Ligaments for DRUJ Instability. Tech Hand Up Extrem Surg 2000;4(3):154-60. Crossref

34. Hearon BF, Frantz LM, Morris HA. The original anatomic reconstruction of palmar and dorsal radioulnar ligaments for distal radioulnar joint instability. J Hand Surg Am 2020;45(11):1092.e1-8. Crossref

35. Luchetti R, Atzei A, Cozzolino R, Fairplay T, Badur N. Comparison between open and arthroscopic-assisted foveal triangular fibrocartilage complex repair for posttraumatic distal radio-ulnar joint instability. J Hand Surg Br 2014;39(8):845-55. Crossref

36. Mathoulin C. Arthroscopic reconstruction of the triangular fibrocartilage complex using a free tendon graft. In: Mathoulin C, editor. Wrist Arthroscopy Techniques. Stuttgart: Thieme Verlagsgruppe; 2015. p.71-4. Crossref 